NBER WORKING PAPER SERIES

CAPITAL MOBILITY AND DEVALUATION IN AN OPTIMIZING MODEL WITH RATIONAL EXPECTATIONS

Maurice Obstfeld

Working Paper No. 557

NATIONAL BUREAU OF ECONOMIC RESEARCH 1050 Massachusetts Avenue Cambridge MA 02138

October 1980

This paper was prepared for the session "A Critical Look at Rational Expectations in Practice" of the September 1980 American Association Meetings, Denver, Colorado. The research reported here is part of the NBER's research program in International studies. Any opinions expressed are those of the author and not those of the National Bureau of Economic Research. 


\title{
Capital Mobility and Devaluation in an Optimizing Model with Rational Expectations
}

\begin{abstract}
This paper examines the effects of exchange-rate policies when individuals maximize lifetime utility on the basis of rational expectations about the future. The institutional framework is a small economy in which the central bank holds the exchange rate fixed at each moment in time, but allows it to depreciate over time according to a pre-announced schedule. In this setting, an unanticipated, discrete devaluation of the currency has no real effects. It occasions only a tranfer of interest-bearing foreign assets from the public to the central bank. An unanticipated, permanent increase in the rate of devaluation, in contrast, causes a sharp fall in consumption, a current-account surplus, and a long-run decline in the reserves of the central bank.
\end{abstract}

Maurice Obstfeld Department of Economics Columbia University New York, NY 10027

(212) $280-5510$ 
This paper examines the effects of exchange-rate policies when individuals maximize lifetime utility on the basis of rational expectations about the future. The economy studied is one in which the authorities allow free mobility of capital under a crawling-peg exchange-rate regime. Many industrializing economies have adopted a crawling peg as a means of reconciling disparate inflation rates at home and abroad, and some recent efforts to use the rate of crawl as an instrument of anti-inflation policy have attracted considerable interest (see Carlos Díaz Alejandro). Tools similar to those employed here have been applied by Guillermo Calvo (1979a) to study this type of exchange-rate management under conditions of capital immobility.

An advantage of the explicit optimization framework is the light it throws on the interaction between private economic decisions and the balance sheets of the government and, particularly, the central bank. Although the literature on open-economy financial policy has largely ignored such considerations--the exceptions include papers by Alan Stockman and myself (1979, 1980a)--the extent to which the public internalizes official asset holdings has obvious consequences for the efficacy of official intervention in asset markets. An implication of the model explored below is that the stock of central-bank reserves, when allowed to earn interest, will be perceived by the public as part of its own wealth. In this setting, devaluation loses its real effects, for a discrete rise in the price of foreign exchange occasions a proportional issue of central-bank money, a transfer of interest-bearing foreign bonds from the public to the bank, and nothing more.

The optimization hypothesis, as applied here, eliminates the indeterminacy typically associated with models assuming rational expectations or perfect foresight. This is an additional advantage, as it provides a firm ground for convergence assumptions that must usually go unjustified. The explicit specification of agents' objective functions leads also to a natural welfare analysis of alternative policies. 


\section{The Model}

The economy I consider is inhabited by a representative household, which derives utility from consuming a single composite commodity and holding real money balances. Household wealth is divided between high-powered money holdings (there is no banking system) and holdings of an internationally-traded bond having a fixed foreign-currency face value. The economy is small, and therefore can influence neither the (positive) world bond rate, $\rho$, nor the foreign-currency price of the consumption good, $\mathrm{P}^{*}$, both of which are taken to be fixed. ${ }^{l}$ The domestic-currency price of consumption, $P$, is linked to the world price by the relationship $P=E P^{*}$, where $E$, the exchange rate, is the price of foreign money in terms of domestic money.

The central bank causes the exchange rate to depreciate according to a preannounced schedule by standing ready at each instant to trade home currency for foreign exchange on the pre-announced terms. This type of exchange-rate regime has been studied, in somewhat different contexts, by Calvo (1979a, 1979b), Paul Krugman, Jorge de Macedo, Carlos Rodriguez, Sweder van Wijnbergen, and others. It is assumed that the official schedulecalls for a constant, non-negative rate of devaluation, $\varepsilon$, which must equal the domestic inflation rate, $\dot{P} / \mathrm{P}$, at all times.

The representative household's instantaneous utility function is written as $u_{t}=u\left(c_{t}, m_{t}\right)$, where $c_{t}$ is the family's consumption rate and $m_{t}$ represents its nominal money holdings, $M_{t}$, deflated by $P_{t}$. The function $u(\cdot, \cdot)$ is positive, twice continuously differentiable, increasing in both its arguments, and strictly concave. Both consumption and money services are normal goods. Maximization of the functional

$$
\int_{0}^{\infty} u_{t} e^{-\Delta_{t}} d t
$$


is the household's lifetime objective. $e^{-\Delta_{t}}$ is the discount factor applied to utility arriving at time $t$; the function $\Delta_{t}$ is defined as

$$
\Delta_{t} \equiv \int_{0}^{t} \delta_{s} d s
$$

where $\delta_{s}$ is the household's instantaneous rate of discount at time $s$. When $\delta_{s} \equiv \delta$, a constant, for all $s$, we have the usual discount factor, $e^{-\Delta t}=e^{-\delta t}$. But to enable the economy to attain a stationary state at the constant world interest rate $\rho$, I will adopt instead the approach of Hirofumi Uzawa, in which the instantaneous discount rate at time $s$ is a positive function of the contemporaneous utility level:

$$
\delta_{\mathbf{s}}=\delta\left(\mathrm{u}_{\mathbf{s}}\right)
$$

It is convenient to endow $\delta(\cdot)$ with the properties

$$
\delta^{\prime}(u), \delta^{\prime \prime}(u), \delta(u)-u \delta^{\prime}(u)>0,
$$

for all u. The assumptions (4) facilitate solution of the household's maximization problem, but are in no way intrinsic to the notion of an endogenous rate of time preference. ${ }^{2}$

In maximizing (1), the family is bound by three constraints. The first is a (stock) wealth constraint, which states that marketable real assets at time $t$, $a_{t}$, must equal the sum of real bond holdings $b_{t}$ and real balances:

$$
a_{t}=b_{t}+m_{t}
$$


The second is a (flow) savings constraint,

$$
\dot{a}_{t}=y+\rho b_{t}+\tau t-c_{t}-\varepsilon m_{t^{\prime}}
$$

real

where $y$ is the economy's (fixed) output, ${ }^{t}{ }$ net/transfers from the government, and $\varepsilon \mathrm{m}_{t}$ the inflation tax on cash balances. The final constraint is the intertemporal budget constraint,

$$
\int_{0}^{\infty}\left(c_{t}+(\varepsilon+\rho) m_{t}-\tau_{t}\right) e^{-\rho t} d t \leq y / \rho+b_{0}+m_{0} .
$$

The consolidated budget constraint of the government and central bank plays a key role in the developments below. It embodies the very important assumption that central-bank reserves earn interest at the world rate, $\rho$. The government makes net transfer payments to domestic residents, but does not consume goods. In the absence of interest-bearing government debt, any excess of transfer payments over central-bank foreign interest earnings must be financed by domestic credit creation. The latter will in general be accompanied by changes in the foreign source component of the money supply, and so, cannot be identified with monetary growth. I assume that the level of government transfers is continuously varied in such a way that the rate of real domestic credit expansion equals $100 \varepsilon$ per cent of the stock of real balances at each moment. This implies a public-sector budget constraint of the form

$$
\tau_{t}-\rho r_{t}=\varepsilon m_{t}
$$

where $r_{t}$ denotes the central bank's real reserve holdings at time $t$. 
II. The Perfect-Foresight Equilibrium Path

For any expected path $\left\{\tau_{t}\right\}$ of transfer payments, maximization of (1) subject to the constraints (5)-(7) yields the household's preferred paths for consumption $\left(\left\{c_{t}^{*}\right\}\right)$, real balances $\left(\left\{m_{t}^{*}\right\}\right)$, and external claims $\left(\left\{b_{t}^{*}\right\}\right)$, together with an implied path for central-bank reserves $\left(\left\{r_{t}^{*}\right\}\right)$. The economy's perfect-foresight equilibrium path has the property that $\left\{\tau_{t}\right\},\left\{m_{t}^{*}\right\}$ and $\left\{r_{t}^{*}\right\}$ are mutually consistent, in the sense that the government's budget constraint, $\tau_{t}=\rho r_{t}^{*}+\varepsilon m_{t}^{*}$, is satisfied at each instant.

The first step in finding this path is to derive necessary conditions for an optimal household plan, contingent on an assumed path $\left\{\tau_{t}\right\}$ of transfers. ${ }^{3}$ Using (2), one can simplify the maximization problem by a change of variables from to $\Delta$ in (1) and (6). The resulting Hamiltonian is

$$
H=\frac{u(c, m)}{\delta(u(c, m))}+\lambda\left\{\frac{y+\rho b+\tau-c-\varepsilon m}{\delta(u(c, m))}\right\}+\gamma\{a-b-m\},
$$

where $\lambda=\lambda_{\Delta}$ is the co-state variable and $\gamma=\gamma_{\Delta}$ is the Lagrange multiplier associated with the wealth constraint. Necessary conditions for an optimal program are

$$
\begin{aligned}
& \lambda=\frac{u_{c}\left(\delta-\delta^{\prime} u\right)}{\delta+\delta u_{c}(y+\rho b+\tau-c-\varepsilon m)}, \\
& u_{m} / u_{c}=\varepsilon+\rho, \\
& \dot{\lambda}=\delta(u) \frac{d \lambda}{d \Delta}=\lambda(\delta(u)-\rho),
\end{aligned}
$$

and the flow constraint (6). Given $\varepsilon+\rho,(11)$ defines real money demand 
as an implicit function $\phi$ of consumption, with

$$
\phi^{\prime}(c)=-\frac{u_{c m}-(\varepsilon+\rho) u_{c C}}{u_{m m}-(\varepsilon+\rho) u_{c m}}>0 .
$$

The perfect-foresight assumption is imposed by adding to (10) - (12) the requirement that anticipated transfers $\left\{\tau_{t}\right\}$ and actual transfers $\left\{\rho r_{t}+\varepsilon m_{t}\right\}$ coincide. The resulting system of differential equations satisfies both the conditions necessary for optimality and the consistency condition linking expected transfers and the government budget constraint. Using the definition of $\dot{\phi}$, the system is described by the equations

$$
\begin{aligned}
& \lambda=\frac{u_{c}(c, \phi(c))\left\{\delta(u(c, \phi(c)))-\delta^{\prime}(u(c, \phi(c))) u(c, \phi(c))\right\}}{\delta(u(c, \phi(c)))+\delta^{\prime}(u(c, \phi(c))) u_{c}(c, \phi(c))(y+\rho f-c)}, \\
& \dot{\lambda}=\lambda(\delta(u(c, \phi(c)))-\rho), \\
& \dot{f}=y+\rho f-c,
\end{aligned}
$$

where $f \equiv b+r$ denotes the stock of claims on foreigners owned by the country as a whole. Equation (16) displays the equilibrium rate of external asset accumulation as the difference between national income and absorption. It is derived by noting that $\dot{a}=\dot{b}+\dot{m}$, while $\dot{m}$ must equal $\dot{r}$ because domestic credit expansion just compensates money-holders for the real depreciation of their cash balances. 4

The stationary-state levels of consumption and foreign claims are those such that $\dot{\lambda}=\dot{f}=0$. By writing (14)-(16) as a system in $c$ and $f$, and then 
taking its linear approximation in a neighborhood of this stationary state, one obtains a graphical representation of the perfect-foresight equilibrium path. Equation (14) implies a relationship of the form $c=c(\lambda, f)$; thus,

$$
\dot{c}=c_{\lambda} \dot{\lambda}+c_{f} \dot{f} \equiv \theta(c, f),
$$

where (14)-(16) have been used to eliminate $\dot{\lambda}, \lambda$, and $\dot{f}$ in defining $\theta(\cdot, \cdot)$. The local linearization of (17) is

$$
\begin{aligned}
\dot{c} & \simeq \bar{\theta}_{c}(c-\bar{c})+\bar{\theta}_{f}(f-\bar{f}) \\
& =\frac{\bar{u}_{c}(\rho-\bar{\delta} \cdot \bar{u}) \bar{\delta}^{\prime} \bar{u}_{m} \bar{\phi}^{\prime}}{\Delta}(c-\bar{c})+\frac{\bar{u}_{c}^{2} \bar{\delta}^{\prime}(\rho-\bar{\delta} \cdot \bar{u}) \rho}{\Delta}(f-\bar{f}) ;
\end{aligned}
$$

in (18), a bar indicates a stationary-state value, and

$$
\Delta=\left(\rho-\bar{\delta}^{\prime} \bar{u}\right)\left(\bar{u}_{C c}+\bar{u}_{c m} \bar{\phi}^{\prime}-\bar{u}_{c}\left(\bar{\delta}^{\prime} / \rho\right) \bar{u}_{m} \bar{\phi}^{\prime}\right)-\bar{u}_{c} \bar{u}^{\prime \prime}\left(\bar{u}_{c}+\bar{u}_{m} \bar{\phi}^{\prime}\right)<0 .
$$

Figure 1 displays the phase portrait of the system described by (16) and (18). The locus of points along which $\dot{\mathrm{f}}=0$ is upward-sloping, with foreign claims increasing to its right and decreasing to its left. The locus along which $\dot{c}=0$ is negatively sloped; consumption is falling above this schedule and rising below it (for $\bar{\theta}_{C}<0$ ):

The stationary state $(\bar{c}, \bar{f})$ is a saddlepoint: for an initial value $f_{0}$ of the predetermined variable, there is a unique initial consumption level $c_{0}$ placing the economy on a convergent path. Any consumption level exceeding $c_{0}$ initiates a trajectory along which the intertemporal budget constraint (7) is violated. Such paths are infeasible, and may thus be ruled out. Paths 


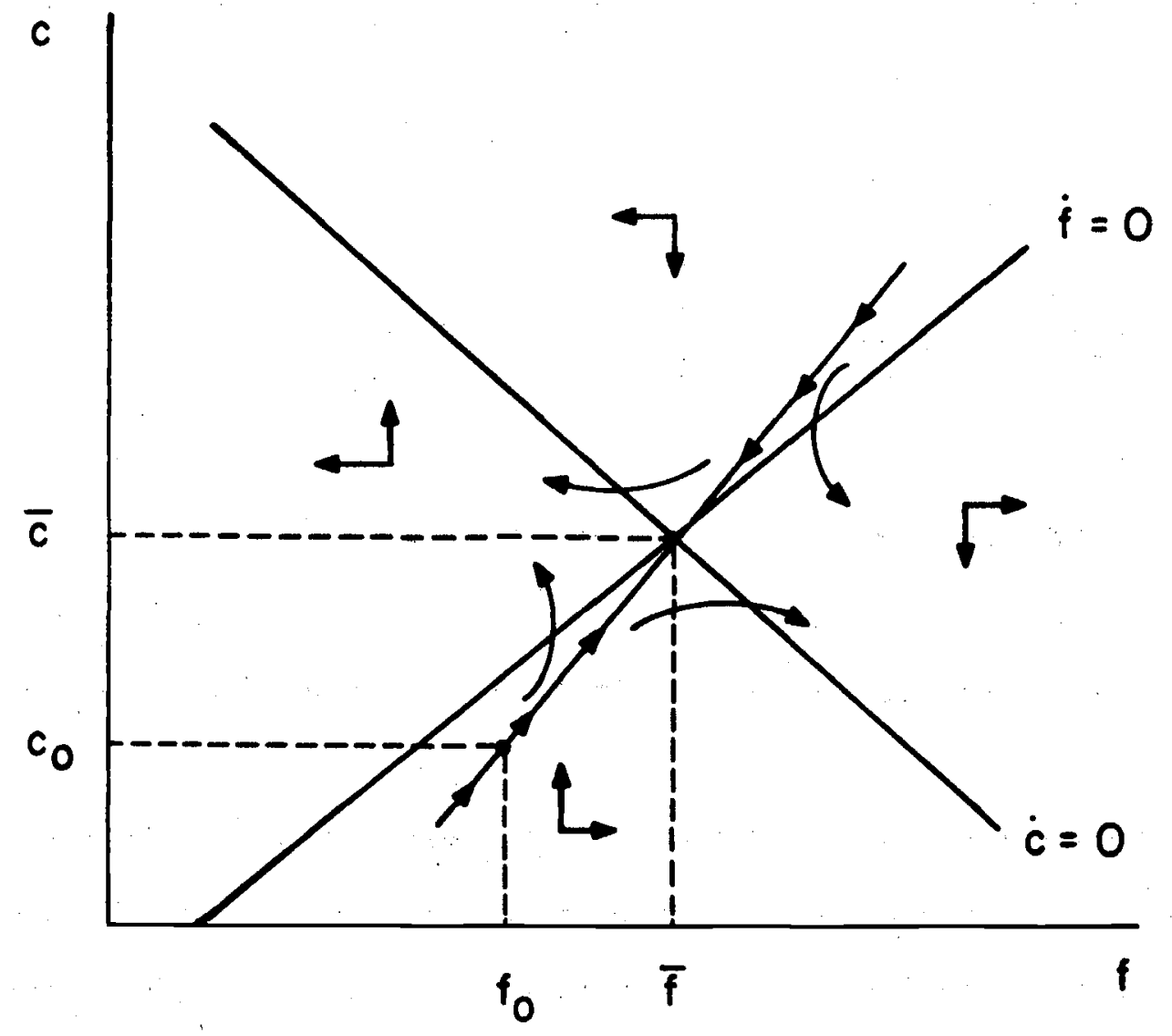

FIGURE 1 
initiated by consumption levels below $c_{0}$ are feasible, but are not optimal from the household's standpoint, given the associated path of expected future transfer payments. The convergent trajectory can be shown to be optimal as well as feasible. It must, therefore, be the economy's perfectforesight equilibrium path. For a given initial stock of external claims, the equilibrium consumption level is unambiguously determined.

\section{Exchange-Rate Policies}

To illustrate the workings of the model, I consider in this section two types of exchange-rate policy, a one-time, unanticipated devaluation of the currency (a discrete increase in E) and a permanent, unanticipated increase in the rate of devaluation, $\varepsilon$. These are the two policies compared by Calvo (1979a) for a utility-maximizing economy in which domestic money is the only privately-owned asset.

An unanticipated devaluation leaves the two schedules in figure 1 unchanged, and has no effect on the national stock of foreign claims, which can change only over time. The devaluation thus leaves the economy at its long-run equilibrium position: it has no real consequences. Just as in the traditional one-asset framework (see Rudiger Dornbusch and Calvo (1979a)), the devaluation brings about a sharp rise in the price level and fall in real balances. But in a setting of capital mobility, the fall in real balances is only momentary. An incipient excess demand for money exerts downward pressure on the exchange rate, and this forces the central bank to intervene in the asset market, purchasing foreign bonds and issuing money until the public's real balances have been restored to their initial level.

It is important to realize why this tranfer of bonds from the public to the central bank reverses the wealth effect on consumption typically associated with the fall in the real value of privately-held, marketable assets (see, e.g., Jacob Frenkel and Rodriguez). Reserves acquired by the bank 
continue to earn interest that must be returned to the public in the form of higher transfer payments. The public, in turn, anticipates and capitalizes this income stream, and so, perceives no change in its overall wealth when real balances are again at their initial level. Accordingly, the devaluation does not alter consumption. While there is an instantaneous increase in reserves, there ensues no flow surplus in the halance of payments or current account. 5 In contrast, an unanticipated increase in the rate of devaluation does have real consequences, for it shifts the $\dot{c}=0$ locus. By (12), the economy's stationary utility level $\bar{u}$ brings its rate of time preference into equality with the world interest rate, and is thus independent of the policy parameter $\varepsilon$. The increase in $\varepsilon$ raises the opportunity cost of holding real balances, inducing a long-run substitution of consumption for real balances along the utility contour $\bar{u}$. This means that the $\dot{c}=0$ locus must shift to the right, as shown in figure 2. In the new stationary state, the higher consumption level is financed by a higher stock of interest-bearing foreign claims. Money is not super-neutral under the present assumptions. 6 What are the characteristics of the transition path? As figure 2 shows, the saddlepath relevant after the increase in $\varepsilon$ passes below the original long-run equilibrium, $(\bar{c}, \bar{f})$. If the economy is initially at rest, there is a sharp fall in consumption, from $\bar{c}$ to $c_{0}^{\prime}$, as the new optimal trajectory is attained. Together with the fall in the real return on money, this occasions a drop in real money demand, accommodated by central-bank sales of foreign-exchange reserves to the public.

The instantaneous equilibrium $\left(c_{0}^{\prime}, \bar{f}\right)$ is a position of current-account surplus; consumption and the national stock of foreign assets grow along the path to $\left(\bar{c}^{\prime}, \bar{f}^{\prime}\right)$, the new long-run equilibrium. Necessary condition 


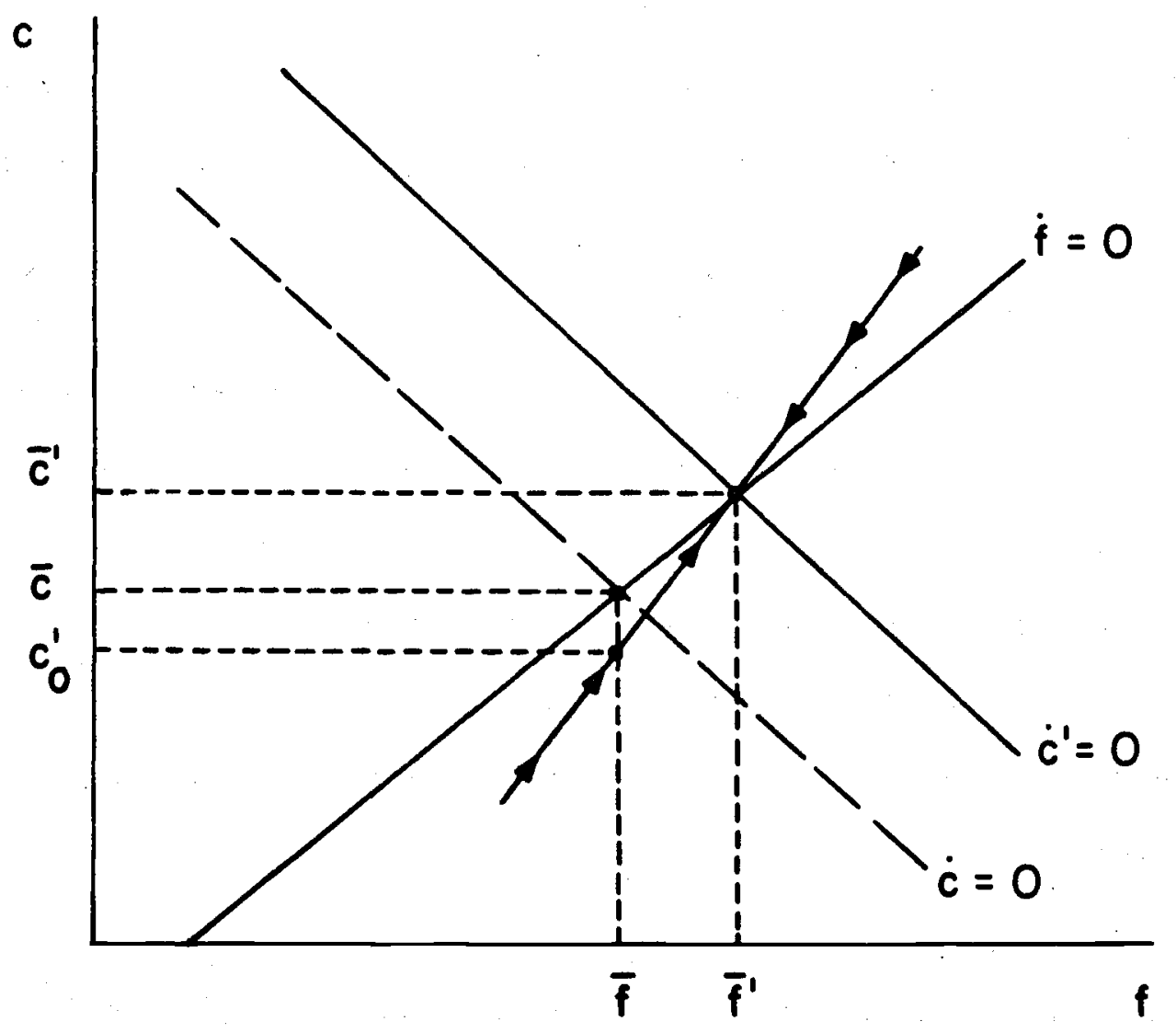

FIGURE 2 
(11) shows that desired real balances grow as well during the adjustment process. The central bank accommodates this growing demand for money by continuous intervention in the foreign exchange market, thereby preventing any deviation of the exchange rate from its announced path and also inducing a rising path of official reserves. Ultimately, however, the reserves gained during the transition do not make up for those lost during the initial portfolio adjustment in reaction to the change in $\varepsilon$. A higher asymptotic level of reserves would be inconsistent with the requirement that real balances be lower in the new stationary state than in the original one.

This time path of reserves and consumption stands in interesting contrast to the one found by Calvo (1979a) in a context of capital immobility. When there is only one asset, there can be no portfolio shift in response to an increase in the rate of depreciation, and so a discrete fall in real balances is precluded. Rather than overshooting their eventual, lower levels, real money and reserves decline monotonically over time. From an initial position of long-run equilibrium, consumption must rise on impact to induce the implied current-account deficit.

In the present setting of capital mobility, the integral of discounted utilities, (1), is lower along the transition path following a rise in $\varepsilon$ than it would have been along the original stationary-state path. This follows from the observation that the household's instantaneous utility falls when $\varepsilon$ is raised, returning to its initial level only in the long run. Thus, an increase in the rate of devaluation has a negative effect on the welfare of economic agents. 
Footnotes

* Assistant Professor, Columbia University. I am grateful for conversations with Guillermo Calvo, and for very helpful comments from Dale Henderson and John Taylor. Financial support from the Columbia University Council for the Social Sciences is acknowledged with thanks.

1. The assumption that $\mathrm{P}^{*}$ is constant implies that bonds are, in effect, indexed to the consumption good.

2. My 1980 papers contain a more complete discussion of the conditions (4).

3. Again, my 1980 papers treat this type of problem in greater detail.

4. The time derivative of the nominal money supply is just the sum of the time derivatives of its foreign and domestic source components, $\dot{\mathrm{M}}_{t}=$ $P_{t} \dot{r}_{t}+\varepsilon M_{t} \cdot$ It follows that $\dot{m}_{t}=\dot{M}_{t} / P_{t}-\varepsilon m_{t}=\dot{r}_{t}$.

5. These conclusions naturally require modification when reserves bear no interest, when some international lending is denominated in domestic currency, or when economic units have finite lives and leave no bequests.

6. This type of monetary non-neutrality has been studied by Robert Lucas and Stanley Fischer in aggregative, closed-economy, rational-expectations models. Portfolio substitution from money to capital provides the mechanism through which anticipated monetary growth affects real variables. 


\section{$\underline{\text { References }}$}

G.A. Calvo, (1979a) "Devaluation: Levels vs. Rates," manuscript, Columbia University, 1979.

, (1979b) "An Essay on the Managed Float--The Small Country Case," manuscript, Columbia University, 1979.

C.F. Díaz Alejandro, "Southern Cone Stabilization Problems," manuscript, Yale University, 1979.

R. Dornbusch, "Real and Monetary Aspects of the Effects of Exchange Rate Changes," in R.z. Aliber, ed., National Monetary Policies and the International Financial System, Chicago 1974.

S. Fischer, "Anticipations and the Nonneutrality of Money," J. Polit. Econ., April 1979, 87, 225-52.

J.A. Frenkel and C.A. Rodriguez, "Portfolio Equilibrium and the Balance of Payments: A Monetary Approach," Amer. Econ. Rev., Sept. 1975, 65, 674-88.

P.R. Krugman, "The Capital Inflows Problem in Less Developed Countries," manuscript, M.I.T., 1979.

R.E. Lucas, Jr., "An Equilibrium Model of the Business Cycle," J. Polit. Econ., Dec. $1975,83,1113-44$.

J. de Macedo, "Exchange Rate Behavior with Currency Inconvertibility," manuscript, Yale University, 1979.

M. Obstfeld, "The Capitalization of Income Streams and the Effects of OpenMarket Policy under Fixed Exchange Rates," manuscript, Columbia University, 1979. Forthcoming, J. Monet. Econ. , (1980a) "Macroeconomic Policy, Exchange-Rate Dynamics, and Optimal Asset Accumulation," manuscript, Columbia University, 1980. 
M. Obstfeld, (1980b) "Aggregate Spending and the Terms of Trade: Is there a Laursen-Metzler Effect?" manuscript, Columbia Uñịersity, 1980,

C.A. Rodriguez, "Managed Float: An Evaluation of Alternative Rules in the Presence of Speculative Capital Flows," manuscript, columbia University, 1978.

A.C. Stockman, "Monetary Control and Sterilization under Pegged Exchange Rates," manuscript, University of Rochester, 1979.

H. Uzawa, "Time Preference, the Consumption Function, and Optimum Asset Holdings," in J.N. Wolfe, ed., Value, Capital, and Growth: Papers in Honor of Sir John Hicks, Chicago, 1968.

S. van Wijnbergen, "Credit Policy, Inflation, and Growth in Developing Countries," unpublished doctoral dissertation, M.I.T., 1980. 